\title{
A case of sudden onset of thyroid storm just before cesarean section manifesting congestive heart failure and pulmonary edema
}

Yuki Sugiyama ${ }^{* \dagger} \mathbb{D}$, Ryusuke Tanaka ${ }^{\dagger}$, Yuki Yoshiyama, Takashi Ichino, Norimasa Hishinuma, Sari Shimizu, Noriko Imai, Kunihiro Mitsuzawa and Mikito Kawamata

\begin{abstract}
Background: Since acute respiratory failure (ARF) is a life-threatening complication, particularly in the gestational period, differential diagnosis and rapid treatment are required. Among the various causes of sudden onset of ARF, thyroid storm is a rare cause in a parturient complicated with well-controlled hyperthyroidism. In this case report, we describe a parturient with hyperthyroidism in whom a thyroid storm manifesting congestive heart failure and pulmonary edema developed just before an emergency ceasarean section, even though hyperthyroidism was well-controlled with antithyroid drugs.

Case presentation: A 36-year-old pregnant woman was diagnosed as having clinical chorioamnionitis, and an emergency cesarean section was performed at 25 weeks of pregnancy. She had a complication of hyperthyroidism accompanied by mild mitral regurgitation, and she had been treated with methimazole. She was treated with ritodrine and $\mathrm{MgSO}_{4}$ for the threat of premature delivery. At the preoperative consultation, her percutaneous oxygen saturation $\left(\mathrm{SpO}_{2}\right)$ was $98 \%$ on room air. When she was admitted to the operating room, her heart rate and blood pressure were 130 beats/min and 196/78 mmHg, respectively. $\mathrm{SpO}_{2}$ was $88 \%$ on room air without any symptoms; however, just after starting oxygen administration via a facemask, she complained of severe respiratory distress and became agitated. Partial pressure of arterial oxygen was $108 \mathrm{mmHg}$ with an inspiratory oxygen fraction of 1.0. Chest radiography revealed pulmonary congestion, and transesophageal echocardiography revealed normal right ventricular function without an embolus and severe mitral regurgitation with preserved left ventricular function. Contrast-enhanced computed tomography after the operation revealed no pulmonary embolus but revealed a pulmonary effusion, and free triiodothyronine level was increased at the onset of dyspnea. Therefore, we diagnosed the causes of sudden onset of dyspnea as pulmonary edema and congestive heart failure induced by a thyroid storm.
\end{abstract}

Conclusion: Sudden onset of a thyroid storm just before a cesarean section occurred in a patient with several risk factors of thyroid storm and pulmonary edema, including pregnancy, treatment with tocolytic agents, and infection. The involvement of these multiple factors was considered to be the cause of the sudden onset of the thyroid storm and the cause of rapidly progressive pulmonary edema.

Keywords: Thyroid storm, Pulmonary edema, Ritodrine, $\mathrm{MgSO}_{4}$, Mitral regurgitation

\footnotetext{
* Correspondence: ysugiyama@shinshu-u.ac.jp

${ }^{\dagger}$ Equal contributors

Department of Anesthesiology and Resuscitology, Shinshu University School

of Medicine, 3-1-1, Asahi, Matsumoto, Nagano 390-8621, Japan
} 


\section{Background}

Acute respiratory failure (ARF) during the gestational period is sometimes life-threatening, and early differential diagnosis and rapid treatment are required. Pulmonary edema, pulmonary embolism, and peripartum cardiomyopathy are critically important causes of ARF, and the onset pattern may be useful in making the differential diagnosis. Among these diseases, pulmonary edema is usually considered to have a gradual onset; however, we experienced rapidly progressive pulmonary edema in a parturient complicated with well-controlled hyperthyroidism just before an emergency ceasarean section. The cause of the rapidly progressive pulmonary edema was considered to be sudden onset of a thyroid storm, which is rare, especially in patients with well-controlled hyperthyroidism.

\section{Case presentation}

A 36-year-old pregnant woman was diagnosed as having clinical chorioamnionitis, and an emergency cesarean section was performed at 25 weeks of her second pregnancy. At 16 weeks of gestation, she was diagnosed as having hyperthyroidism for the first time. She presented with proptosis and occasional sweating and palpitations. Her heart rate (HR) and blood pressure (BP) were 100 beats/min and 112/65 $\mathrm{mmHg}$, respectively. Her goiter was visible and palpable. The levels of thyroidstimulating hormone, free triiodothyronine (T3), and free thyroxine (T4) were $0.005 \mu \mathrm{U} / \mathrm{ml}$ (normal range, $0.34-3.5 \mu \mathrm{U} / \mathrm{ml}), 16.25 \mathrm{pg} / \mathrm{ml}(2.0-4.0 \mathrm{pg} / \mathrm{ml})$ and 2.62 $\mathrm{ng} / \mathrm{dl}(1.0-2.0 \mathrm{ng} / \mathrm{dl})$, respectively. Although chest radiography revealed no abnormality (Fig. 1a), transthoracic echocardiography revealed mild mitral regurgitation (MR) with tethering (Fig. 1b). Treatment with propylthiouracil (900 mg/day orally) was started. At 22 weeks of gestation, she was admitted to undergo treatment for threatened premature delivery, which started with ritodrine $(50 \mu \mathrm{g} / \mathrm{min})$ and $\mathrm{MgSO}_{4}(1.1 \mathrm{~g} / \mathrm{h})$ from 23 weeks of gestation. The treatment for hyperthyroidism was switched from propylthiouracil ( $900 \mathrm{mg} /$ day orally) to methimazole ( $90 \mathrm{mg} /$ day orally), following the recommendation of guidelines [1, 2]. At 24 weeks of gestation, the doses of the tocolytic agents were changed to $42 \mu \mathrm{g} /$ min for ritodrine and $1.6 \mathrm{~g} / \mathrm{h}$ for $\mathrm{MgSO}_{4}$. Her thyroid hormone level was evaluated every week. One day before the surgery, free T3 level was $5.63 \mathrm{pg} / \mathrm{mL}$ and free T4 level was $2.38 \mathrm{ng} / \mathrm{dL}$. The methimazole dose was then reduced to $60 \mathrm{mg} /$ day.

At 25 weeks and 0 days of gestation, an emergency cesarean section was performed since she developed fever with body temperature of up to $39{ }^{\circ} \mathrm{C}$ and clinical signs of infection and was diagnosed as having clinical chorioamnionitis. At the preoperative consultation on the day of surgery, HR was 100 beats/min and BP was
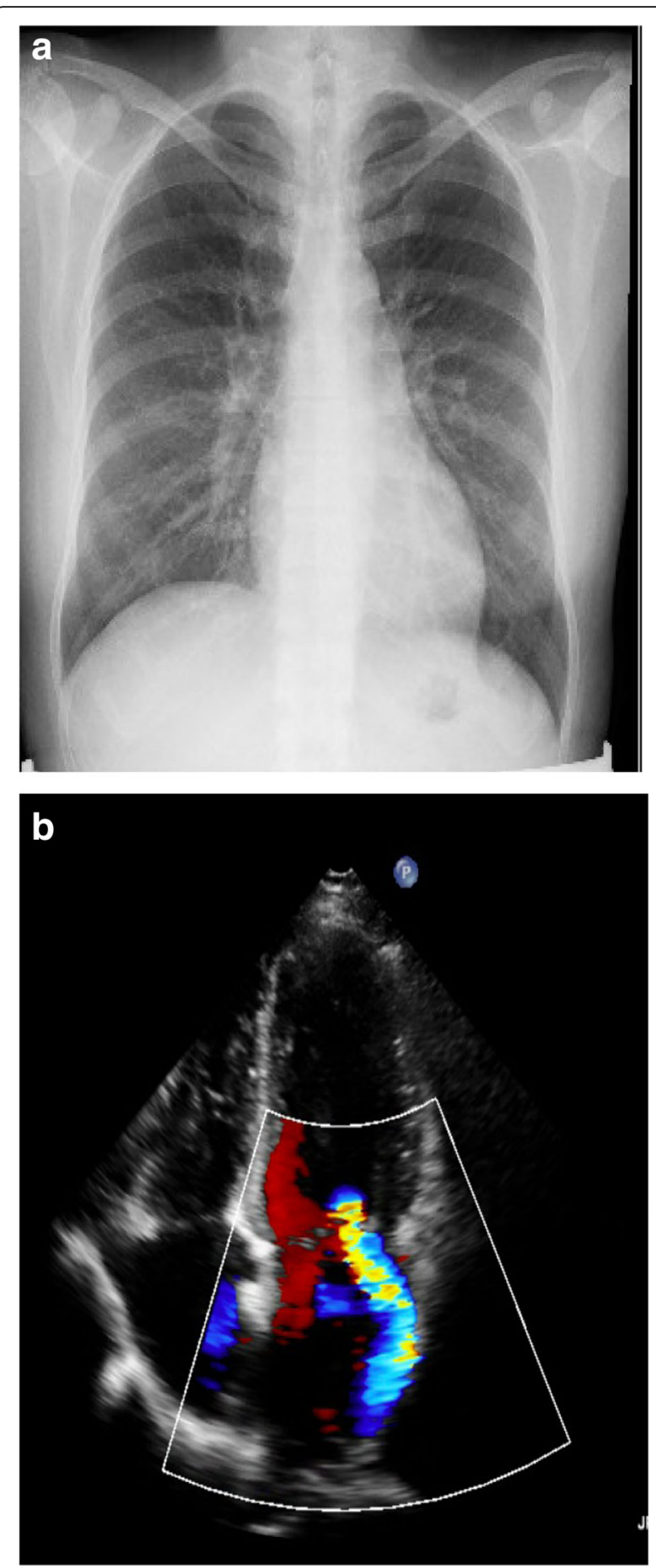

Fig. 1 Preoperative examinations. a Chest radiograph showing no abnormality. b Four-chamber view of a transthoracic echocardiogram showing mild mitral regurgitation with tethering

122/78 mmHg. She did not complain of respiratory distress, and percutaneous oxygen saturation $\left(\mathrm{SpO}_{2}\right)$ was $98 \%$ in room air. The fetus was in good condition. Therefore, we planned a cesarean section under combined spinal-epidural anesthesia (CSEA). 
During transfer from the ward to the operating room, her vital signs were not monitored. Thirty minutes after preoperative consultation, she could move from the stretcher to the operating table by herself without any problem and without any complaint of dyspnea, and then we started monitoring her vital signs. HR, BP, and $\mathrm{SpO}_{2}$ were 130 beats/min, $196 / 78 \mathrm{mmHg}$, and $88 \%$ on room air, respectively. Thus, oxygen was immediately administered at $10 \mathrm{~L} / \mathrm{min}$ via a facemask. Just after that, she complained of severe respiratory distress and became agitated. $\mathrm{SpO}_{2}$ was $92 \%$ with $10 \mathrm{~L} / \mathrm{min}$ oxygen administration. An arterial catheter was inserted, and arterial blood gas analysis revealed partial pressure of arterial oxygen $\left(\mathrm{PaO}_{2}\right)$ of $108 \mathrm{mmHg}$, partial pressure of carbon dioxide of $24.2 \mathrm{mmHg}$, and $\mathrm{pH}$ of 7.513 with a fraction of inspiratory oxygen $\left(\mathrm{FiO}_{2}\right)$ of 1.0. Chest radiography revealed bilateral pulmonary congestion (Fig. 2a). Examination by transthoracic echocardiography was impossible because the patient was struggling against dyspnea and she was unable to maintain a stable position. Mask-assisted ventilation was inadequate for the same reason, although oxygenation continued to exacerbate. To improve her respiratory status, we decided to sedate her as soon as possible, and we therefore changed the anesthesia plan from CSEA to general anesthesia. Twenty minutes after entering the operating room, rapid sequence induction was attempted with 120 $\mathrm{mg}$ of propofol and $80 \mathrm{mg}$ of rocuronium. Simultaneously with the inhibition of spontaneous breathing, $\mathrm{SpO}_{2}$ rapidly decreased to $75 \%$, requiring assisted mask ventilation. One minute later, her trachea was intubated, and the cesarean section was started. Her $\mathrm{SpO}_{2}$ increased to $100 \%$ with $\mathrm{FiO}_{2}$ of 1.0 , and a male baby was delivered $3 \mathrm{~min}$ after the start of surgery. His Apgar score was 5 at $1 \mathrm{~min}$ and 7 at $5 \mathrm{~min}$. She was ventilated via volume-controlled ventilation, at a tidal volume of 6-8 $\mathrm{ml} / \mathrm{kg}$, peak inspiratory pressure of less than 30 $\mathrm{cmH}_{2} \mathrm{O}$ and positive end-expiratory pressure of 5-7 $\mathrm{cmH}_{2} \mathrm{O}$ in accordance with a lung protective strategy.

After parturition, transesophageal echocardiography was immediately performed by a cardiologist and revealed normal right ventricular function without an embolus and severe MR with preserved left ventricular function (ejection fraction $>60 \%$ ) (Fig. 2b). Within 30 min after the start of surgery, HR and BP gradually decreased from 130 to 110 beats/min and from 196/78 to $110 / 55 \mathrm{mmHg}$, respectively. Consistent with the decrease in BP, the MR gradually improved and the $\mathrm{PaO}_{2} / \mathrm{FiO}_{2}$ ratio increased to 187 .

After the operation, contrast-enhanced computed tomography (CT) was performed and revealed no pulmonary embolus, but pulmonary effusion was present. Laboratory data obtained immediately after the dyspnea showed the following values with their normal ranges:
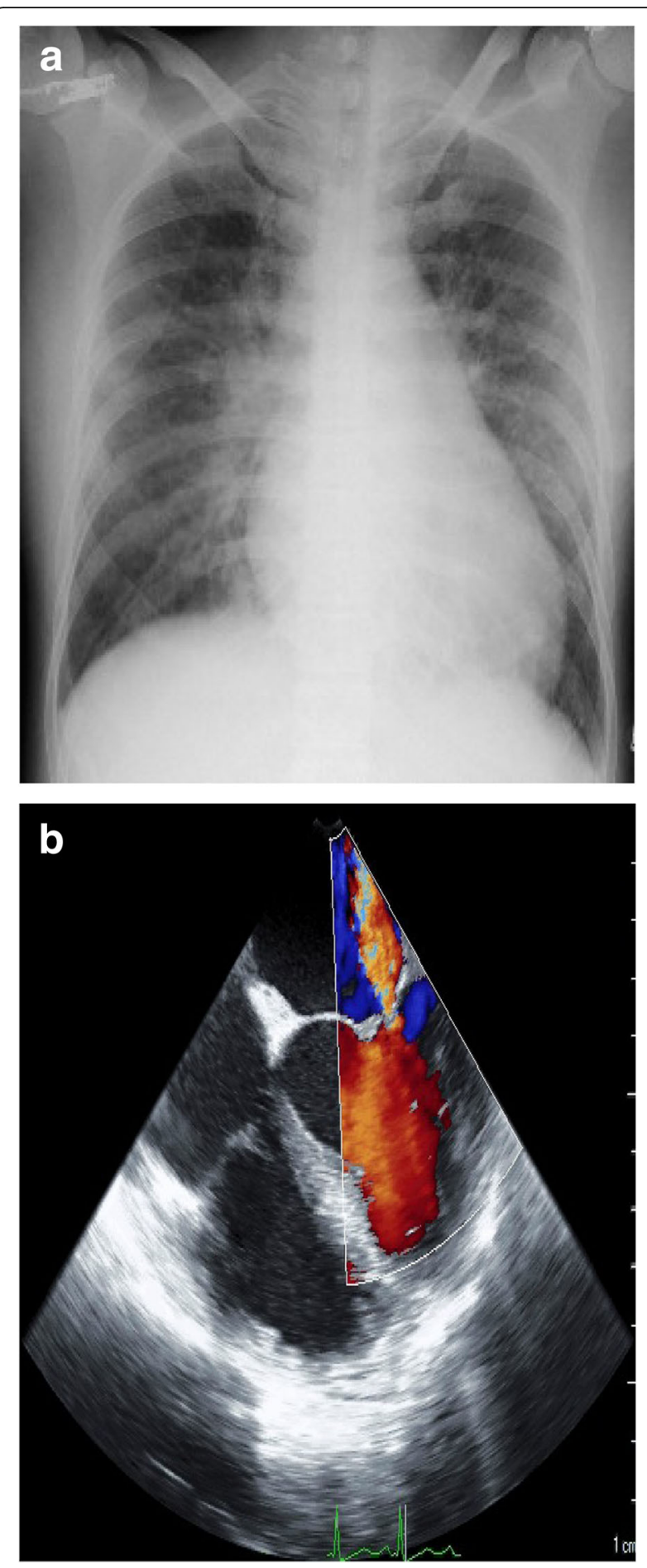

Fig. 2 Examinations after exacerbation of dyspnea. a Chest radiograph showing cardiac enlargement and bilateral pulmonary infiltration. b Four-chamber view of a transesophageal echocardiogram showing severe mitral regurgitation

D-dimer, $5.3 \mu \mathrm{g} / \mathrm{mL}(<1 \mu \mathrm{g} / \mathrm{ml})$; N-terminal B-type natriuretic peptide (NT-pro BNP) $616.7 \mathrm{pg} / \mathrm{mL}(<125 \mathrm{pg} /$ $\mathrm{mL})$; zinc coproporphyrin- $1,<1 \mathrm{pmol} / \mathrm{mL}(<1.6 \mathrm{pmol} /$ 
$\mathrm{mL})$; and sialyl-Tn antigen, $20 \mathrm{U} / \mathrm{mL}(<46 \mathrm{IU} / \mathrm{mL})$. Free T3 level was $8.98 \mathrm{pg} / \mathrm{mL}$ and free T4 level was $2.28 \mathrm{ng} /$ $\mathrm{dL}$. She was transferred to the intensive care unit and treated with intermittent administration of furosemide at $10 \mathrm{mg}$. Her oxygenation gradually improved and her trachea was extubated on postoperative day 1 . At the postoperative interview, she said that she had a paniclike feeling in the operating room. She was discharged from the intensive care unit on postoperative day 1 . On postoperative day 7, transthoracic echocardiography revealed that the MR was trivial. Her clinical course was uneventful thereafter, and she was discharged on postoperative day 11 , continuing methimazole therapy at $20 \mathrm{mg} /$ day.

\section{Discussion}

This case shows the importance of a thyroid storm as a differential diagnosis of ARF, even if respiratory symptoms rapidly progresses. In pregnancy, ARF can be caused by various diseases, and both echocardiography and contrast-enhanced $\mathrm{CT}$ are indispensable for a definite diagnosis. We could not examine her via transthoracic echocardiography before general anesthesia because the patient was struggling against dyspnea and she was unable to maintain a stable position; however, if possible, it is better to make the diagnosis before general anesthesia. In our situation, we considered that general anesthesia could improve her respiratory condition and a rapid diagnosis could be reached via transesophageal echocardiography.

We initially assumed that the cause of ARF was pulmonary embolism because of its sudden onset; however, intraoperative transesophageal echocardiography revealed no right ventricular load and preserved left ventricular function. In addition, postoperative contrastenhanced CT and laboratory examination revealed no evidence of pulmonary embolism. From these findings, the cause of ARF in this case was considered to be pulmonary edema induced by congestive heart failure resulting from exacerbated MR caused by tachycardia and increase of afterload.

The prevalence of pulmonary edema in pregnant women has been reported to be $0.08 \%$, and preeclampsia, congestive heart failure, hyperthyroidism, administration of tocolytic agents, and fluid overload are known to be major causes of pulmonary edema [3, 4]. Hyperthyroidism occurs in $0.2 \%$ of pregnant women [3] and is frequently accompanied by MR. A report showed that moderate MR was present in 13\% of patients with hyperthyroidism [5]. Papillary muscle dysfunction has been proposed as the possible mechanism of MR complicated with hyperthyroidism, and MR is curable after treatment of the hyperthyroidism [5]. At diagnosis, our patient's thyroid hormone levels were high $(16.25 \mathrm{pg} / \mathrm{mL}$ for free
T3 and $2.62 \mathrm{ng} / \mathrm{dL}$ for free T4), and mild MR appeared as a complication. Thus, treatment was started, and her thyroid hormone levels were lowered to the recommended levels $[1,2]$ on the day before surgery. However, free T3 level was increased at the onset of dyspnea, and other symptoms such as agitation, tachycardia, and congestive heart failure were present. We therefore considered that rapidly progressive pulmonary edema was caused by sudden onset of a thyroid storm.

A thyroid storm is often triggered by severe physical or mental stress. Criteria for the diagnosis of thyroid storm are (1) presence of thyrotoxicosis (elevated free $\mathrm{T} 3$ and/or thyroxine T4 levels) and at least one central nervous system (CNS) manifestation plus one of the following: fever $\left(38{ }^{\circ} \mathrm{C}\right.$ or higher), tachycardia (130 beats/min or faster), congestive heart failure, or gastrointestinal/hepatic manifestations, or (2) presence of thyrotoxicosis and three or more of the manifestations just listed other than CNS manifestations [6]. In our case, it was difficult to determine whether the symptoms (fever, tachycardia, agitation, congestive heart failure) were caused by a thyroid storm or were simply symptoms of underlying diseases that are possibly triggered by a thyroid storm. In such a situation, the symptoms should be regarded as secondary to thyroid storm [6]; therefore, a thyroid storm occurred in this case and it was considered to be mainly triggered by infection. Drugs used for treatment of a thyroid storm to lower thyroid hormones are antithyroid drugs, inorganic iodine, and bile acid sequestrants, and other drugs to control the systemic manifestations are $\beta$-blockers, glucocorticoids, and acetaminophen [7]. Although we did not use these drugs for systemic manifestations because the vital signs and oxygenation improved without these drugs, it might have been better to use these drugs.

There are many case reports on thyroid storm [3, 8-14]. However, the clinical features described in those reports are different from the case reported here based on the following points. First, hyperthyroidism had been treated and controlled during pregnancy in our patient $[3,8,9]$. Second, acute pulmonary edema rapidly developed just before anesthetic induction; our patient had not received any anesthetic or undergone a surgical procedure $[10,14]$. Third, our patient did not suffer from either cardiac failure or lethal arrhythmia. These clinical features of the thyroid storm that our patient experienced have not been described in previous reports $[8,9,11-13]$. Thus, we thought that other exacerbating factors might have played pivotal roles in the sudden manifestation of the symptoms of a thyroid storm and rapidly progressive pulmonary edema.

Ritodrine as a $\beta$-adrenergic agonist and $\mathrm{MgSO}_{4}$ were simultaneously used as tocolytic therapy at low doses; the recommended dose for ritodrine is $50-150 \mu \mathrm{g} / \mathrm{min}$ 
and that for $\mathrm{MgSO}_{4}$ is $1-2 \mathrm{~g} / \mathrm{h}$ [15]. Ritodrine is a wellknown cause of thyroid storm, and both ritodrine and $\mathrm{MgSO}_{4}$ are well-known causes of pulmonary edema induced by cardiovascular and/or renal changes that increase hydrostatic pressure [16]. The incidence rates of pulmonary edema caused by ritodrine and $\mathrm{MgSO}_{4}$ are thought to be approximately 0.25 and $8.5 \%$, respectively $[16,17]$, and the risk of pulmonary edema significantly increases when a $\beta$-adrenergic agonist and $\mathrm{MgSO}_{4}$ are simultaneously administered.

Our patient developed fever due to chorioamnionitis, with a body temperature of up to $39{ }^{\circ} \mathrm{C}$, on the day of surgery. Infection is also a known cause of thyroid storm and an exacerbating factor of pulmonary edema because it increases vascular permeability. Water content in the patient's lungs was supposed to have risen at the time of the preoperative consultation, although she did not complain of dyspnea and $\mathrm{SpO}_{2}$ was $98 \%$ in room air. In this situation, emotional stress related to the emergency cesarean section and agitation induced by a thyroid storm occurred when entering the operating room and acted as a final trigger of rapidly progressive pulmonary edema. This mental stress might have induced the increase in the afterload and diastolic dysfunction by tachycardia followed by exacerbation of MR. The elevated levels of NT-pro-BNP might have reflected this cardiac overload, although hyperthyroidism itself also increases the level of NT-pro-BNP [18]. The multiple and overlapping risk factors of pulmonary edema and thyroid storm were considered to have predisposed the patient to rapidly progressive pulmonary edema.

\section{Conclusions}

We treated a sudden onset of thyroid storm just before a cesarean section manifesting congestive heart failure and rapidly progressive pulmonary edema. This case indicates that in a patient with multiple risk factors, thyroid storm and pulmonary edema are likely to develop suddenly even if each preoperative complication was being carefully treated.

\footnotetext{
Abbreviations

ARF: Acute respiratory failure; BP: Blood pressure; CNS: Central nervous system; CSEA: Combined spinal-epidural anesthesia; CT: Computed tomography; $\mathrm{FiO}_{2}$ : Fraction of inspiratory oxygen; HR: Heart rate; MR: Mitral regurgitation; NT-pro-BNP: N-terminal B-type natriuretic peptide; $\mathrm{PaO}_{2}$ : Partial pressure of arterial oxygen; $\mathrm{SpO}_{2}$ : Percutaneous oxygen saturation; T3: Triiodothyronine; T4: Thyroxine
}

\section{Acknowledgements}

The authors would like to thank the patient and her family members.

\section{Authors' contributions}

YS, RT, and YY made a clinical diagnosis and decision. YS and RT drafted the manuscript. $\mathrm{Tl}, \mathrm{NH}, \mathrm{SS}, \mathrm{NI}$, and $\mathrm{KM}$ supervised the clinical diagnosis and decision. MK supervised the manuscript drafting. All authors read and approved the final manuscript.

\section{Competing interests}

The authors declare that they have no competing interests.

\section{Consent for publication}

Written informed consent was obtained from the patient for publication of this case report and any accompanying images. A copy of the written consent is available for review by the editor-in-chief of this journal.

\section{Publisher's Note}

Springer Nature remains neutral with regard to jurisdictional claims in published maps and institutional affiliations.

Received: 30 October 2016 Accepted: 20 April 2017

Published online: 26 April 2017

References

1. De Groot L, Abalovich M, Alexander EK, Amino N, Barbour L, Cobin RH, et al. Management of thyroid dysfunction during pregnancy and postpartum: an Endocrine Society clinical practice guideline. J Clin Endocrinol Metab. 2012:97:2543-65.

2. Stagnaro-Green A, Abalovich M, Alexander E, Azizi F, Mestman J, Negro R, et al. Guidelines of the American Thyroid Association for the diagnosis and management of thyroid disease during pregnancy and postpartum. Thyroid. 2011;21:1081-125.

3. Pugh S, Lalwani K, Awal A. Thyroid storm as a cause of loss of consciousness following anaesthesia for emergency caesarean section. Anaesthesia. 1994:49:35-7.

4. Sciscione AC, Ivester T, Largoza M, Manley J, Shlossman P, Colmorgen GH. Acute pulmonary edema in pregnancy. Obstet Gynecol. 2003:101:511-5.

5. Merce J, Ferras S, Oltra C, Sanz E, Vendrell J, Simon I, et al. Cardiovascular abnormalities in hyperthyroidism: a prospective Doppler echocardiographic study. Am J Med. 2005;118:126-31.

6. Akamizu T, Satoh T, Isozaki O, Suzuki A, Wakino S, Iburi T, et al. Diagnostic criteria, clinical features, and incidence of thyroid storm based on nationwide surveys. Thyroid. 2012;22:661-79.

7. De Leo S, Lee SY, Braverman LE. Hyperthyroidism. Lancet. 2016. doi:10.1016/ S0140-6736(16)00278-6.

8. Okuda N, Onodera M, Tsunano Y, Nakataki E, Oto J, Imanaka H, Nishimura M. Acute cardial failure in a pregnant woman due to thyrotoxic crisis. Case Rep Cardiol. 2012. doi:10.1155/2012/393580.

9. Kagawa T, Terui K, Gotoh R, Yamada H, Obayashi Y, Kaneko M. Cesarean section in a patient with uncontrolled hyperthyroidism, preeclampsia, and congestive heart failure. Masui. 1996;45:230-4.

10. Hirosaki S, Wakamatsu M, Yoko H. Therapeutic role of plasma exchange in thyroid crisis with multiple organ failure: a case report. J Jpn Soc Clin Anesth. 2015;36:601-6.

11. Ueno A, Yamamoto T, Sato N, Tanaka K. Ventricular fibrillation associated with early repolarization in a patient with thyroid storm. J Interv Card Electrophysiol. 2010;29:93-6.

12. Kobayashi H, Haketa A, Abe M, Tahira K, Hatanka Y, Tanaka S, et al. Unusual manifestation of Graves' disease: ventricular fibrillation. Eur Thyroid J. 2015;4:207-12.

13. Ando T, Henmi T, Haruta D, Haraguchi A, Ueki I, Horie I, et al. Graves'disease complicated by ventricular fibrillation in three men who were smokers. Thryroid. 2011:21:1021-5.

14. Wolfson B, Smith K. Cardiac arrest following minor surgery in unrecognized thyrotoxicosis: a case report. Anesth Analg. 1968;47:672-6.

15. Japan Society of Obstetrics and Gynecology: Guideline for Obstetrical Practice in Japan 2014. http://www.jsog.or.jp/activity/pdf/gl_sanka_2014.pdf. Accessed 14 Sep 2016.

16. Samol JM, Lambers DS. Magnesium sulfate tocolysis and pulmonary edema: the drug or the vehicle? Am J Obstet Gynecol. 2005:192:1430-2.

17. Lamont RF. The pathophysiology of pulmonary oedema with the use of beta-agonists. BJOG. 2000;107:439-44.

18. Schultz M, Faber J, Kistorp C, Jarløv A, Pedersen F, Wiinberg N, et al. Nterminal-pro-B-type natriuretic peptide (NT-pro-BNP) in different thyroid function states. Clin Endoclinol. 2004:60:54-9. 